\title{
A CAPACIDADE INOVATIVA E O DESEMPENHO ECONÔMICO-FINANCEIRO DE EMPRESAS INOVADORAS BRASILEIRAS
}

\author{
*Kléber Formiga Miranda \\ mirandakf@ufersa.edu.br \\ **Alessandra Carvalho de Vasconcelos \\ alegallon@terra.com.br \\ **Márcia Martins Mendes de Luca \\ marciadeluca@ufc.br \\ ***José Ednilson de Oliveira Cabral \\ ednilsoncabral@gmail.com \\ *Universidade Federal Rural do Semi-Árido - Mossoró, RN / Brasil \\ **Universidade Federal do Ceará - Fortaleza, CE / Brasil \\ ***Universidade de Fortaleza - Fortaleza, CE / Brasil
}

http://dx.doi.org/10.1590/1413-2311.0082014.47273

Recebido em 16/03/2014

Aprovado em 09/04/2015

Disponibilizado em 01/08/2015

Avaliado pelo sistema "double blind review"

Revista Eletrônica de Administração

Editor: Luís Felipe Nascimento

ISSN 1413-2311 (versão "on line")

Editada pela Escola de Administração da Universidade Federal do Rio Grande do Sul.

Periodicidade: Quadrimestral

Sistema requerido: Adobe Acrobat Reader.

\section{RESUMO}

Com base nos pressupostos teóricos da Visão Baseada em Recursos (VBR), considerando a utilização de recursos disponíveis internamente nas organizações para manutenção de sua vantagem competitiva por meio da diferenciação, a pesquisa analisa a relação entre a capacidade inovativa e o desempenho econômico-financeiro de empresas brasileiras. A amostra foi extraída a partir das empresas listadas na BM\&FBovespa consideradas inovadoras, segundo o IBI. As variáveis de capacidade inovativa coletadas a partir das PINTECs 2005 e 2008 e de desempenho através do Economática ${ }^{\circledR}$ foram tratadas por meio de análises de correlação e de regressão. Os resultados indicam que os desempenhos econômico (ROA) e operacional (EBITDA/Ativo Total) não são significativamente influenciados pela capacidade inovativa. No entanto, quando se separa a capacidade inovativa por seus componentes (inovação de produto, processo, organizacional e marketing), observa-se uma influência positiva de inovação de produto sobre ambos os desempenhos. Por sua vez, o desempenho de valor (MVA) é influenciado positiva e significativamente pela capacidade inovativa. Esses resultados sugerem melhores resultados contábeis quando as empresas inovam no produto e maior geração de valor pelo mercado ao possuir um portfólio diversificado de inovação, ou seja, maior capacidade inovativa. Não se pode, entretanto, 


\title{
EMPRESAS INOVADORAS BRASILEIRAS
}

negligenciar as inovações em processo, organizacional e marketing. A pouca relação dessas inovações, perceptíveis no âmbito interno da empresa, com o desempenho pode residir nas diferentes estratégias inovativas adotadas em prol do objetivo principal de cada empresa.

Palavras-Chave: Capacidade inovativa; Desempenho econômico-financeiro; Vantagem competitiva. VBR.

\section{INNOVATIVE CAPACITY AND THE ECONOMIC AND FINANCIAL PERFORMANCE OF BRAZILIAN INNOVATIVE COMPANIES}

\begin{abstract}
Based on the theoretical premises of the Resource Based View (RBV) and considering the use of internally available resources at organizations for the maintenance of a competitive edge by means of differentiation, this research evaluates the relation between innovative capacity and economic and financial performance in Brazilian companies. The sample was made up of companies listed on the BM\&FBovespa which were considered innovative according to the IBI. The variables of innovative capacity collected from 2005 to 2008 PINTECs and performance by means of Economática ${ }^{\circledR}$ were submitted to an analysis of regression and correlation. Results indicate that economic (ROA) and operational (EBITDA/Total Active) performances are not significantly influenced by innovative capacity. However, when one breaks innovative capacity down to its components (product innovation, organizational process and marketing), a positive influence of product innovation is observed on both performances. On the other hand, value performance (MVA) is influenced positively and significantly by innovative capacity. These results hint at better accounting results when companies innovate in products and greater generation of market value when they display a diversified portfolio of innovation, that is, greater innovative capacity. One cannot, however, neglect the innovations in organizational process and marketing. There is little relation between these innovations, perceptible inside companies, and performance and that might be due to different innovative strategies adopted for the benefit of each company's main objective.
\end{abstract}

Keywords: Innovative capacity; Economic and financial performance; Competitive advantage. RBV.

\section{LA CAPACIDAD INNOVATIVA Y EL DESEMPEÑO ECONÓMICO-FINANCIERO DE EMPRESAS INNOVADORAS BRASILEIRAS}

\section{RESUMEN}

Con base en las determinaciones teóricas de la Visión Basada en Recursos (VBR), considerando la utilización de recursos disponibles internamente en las organizaciones para la manutención de su ventaja competitiva por medio de la diferenciación, el estudio analiza el desempeño económico-financiero de empresas brasileras. La muestra se extrajo a partir de las empresas listadas en la BM\&FBovespa, consideradas innovadoras según el IBI. Las variables de capacidad innovativa recolectadas a partir de las PINTECs 2005 y 2008 y de desempeño a

REAd | Porto Alegre - Edição 81 - N 2 - maio/agosto 2014 - p. 269-299 
Kléber Formiga Miranda, Alessandra Carvalho de Vasconcelos, Márcia Martins Mendes de Luca \& José Ednilson de Oliveira Cabral

través del Economática ${ }^{\circledR}$ fueron tratadas por medio de análisis de correlación y de regresión. Los resultados indican que los desempeños económico (ROA) y operacional (EBITDA/Activo Total) no son significativamente influenciados por la capacidad innovativa. No obstante, cuando se separa la capacidad innovativa por sus componentes (innovación, producto, proceso, organizacional y marketing) se observa una influencia positiva de la innovación de producto sobre ambos desempeños. Por su parte, el desempeño de valor (MVA) es influenciado positiva y significativamente por la capacidad innovativa. Estos resultados sugieren mejores resultados contables cuando las empresas innovan en el producto, y una mayor generación de valor por parte del mercado al poseer un portafolio diversificado de innovación, o sea, una mayor capacidad innovativa. Sin embargo, no podemos ignorar las innovaciones en proceso, organizacional y marketing. La poca relación de esas innovaciones, perceptibles en el ámbito interno de la empresa, con el desempeño, puede residir en las diferentes estrategias innovativas adoptadas en pro del objetivo principal de cada empresa.

Palabras Clave: Capacidad innovativa; Desempeño económico-financiero; Ventaja competitiva. VBR.

\section{INTRODUÇÃO}

A diferenciação, como vantagem competitiva, remete à busca pela continuidade das empresas como forma de garantir a perpetuação de seu desenvolvimento frente aos concorrentes. Algumas pesquisas sobre essa temática desencadearam na teoria denominada Visão Baseada em Recursos (VBR) ou Resource-Based View (RBV), destacando-se como seus idealizadores Penrose (1959), Wernerfelt (1984) e Barney (1991).

Para a VBR, a competitividade empresarial emerge da diferenciação na utilização dos recursos internos disponíveis ou gerados pelas empresas, estimulando a concepção da estratégia de "dentro para fora" por meio de sua capacidade inovativa. Esta pesquisa considera elementos de capacidade inovativa os tipos de inovação definidos pelo Manual de Oslo (OECD, 2005), em consonância com as proposições de Schumpeter (1988), quais sejam: a inovação de produto/serviço, a inovação de processo, a inovação organizacional e a inovação em marketing. Esses tipos de inovação são também considerados em Ferreira, Marques e Barbosa (2007), que atribuem a esses elementos o papel de determinantes do processo inovativo das empresas. Dessa forma, a definição constitutiva para a capacidade inovativa consiste, nessa pesquisa, na ocorrência de inovação de produto, inovação de processo, inovação organizacional e inovação em marketing, nas empresas da amostra, durante o período pesquisado.

Tendo-se a inovação como elemento-chave na competitividade das empresas, conjectura-se que a capacidade inovativa tem reflexo positivo no desempenho empresarial. A aproximação entre a inovação e o desempenho das organizações é verificada quando se 
A CAPACIDADE INOVATIVA E O DESEMPENHO ECONÔMICO-FINANCEIRO DE

\section{EMPRESAS INOVADORAS BRASILEIRAS}

reconhece ser crescente o número de empresas mobilizadas na busca por conhecimento, experiência e capacidade tecnológica para desenvolver produtos, serviços e/ou processos inovadores. Nesta pesquisa, o desempenho empresarial é analisado em seus aspectos econômico, operacional e de valor.

A relação entre elementos de inovação e o desempenho empresarial foi foco de pesquisas com resultados dispersos. As justificativas para as assimetrias são identificadas em Facó, Duarte e Csillag (2009) e Santos (2009): base de dados/amostra; Facó, Duarte e Csillag (2009), Brito, Brito e Morganti (2009): setores analisados; Teh, Kayo e Kimura (2008), Brito, Brito e Morganti (2009) e Santos (2009): procedimentos estatísticos ou tratamento dos dados/variáveis. Essas divergências motivam a continuidade desses estudos como forma de contribuir com a formação de um melhor entendimento sobre o relacionamento da temática inovação com o desempenho empresarial, indicada como relevante para o meio corporativo.

Nesse contexto, o estudo investiga a seguinte questão: Qual a relação entre a capacidade inovativa de empresas brasileiras e o seu desempenho econômico-financeiro?

Levando-se em conta estudos (FERREIRA; MARQUES; BARBOSA, 2007; TEH; KAYO; KIMURA, 2008; SANTOS, 2009; BRITO; BRITO; MORGANTI, 2009; MIRANDA; GALLON; SILVA-FILHO, 2011, MIRANDA; GALLON; NOGUEIRA, 2011), cujos resultados são convergentes sobre a existência de relação positiva entre variáveis de inovação e o desempenho das empresas, ainda que analisados em contextos empresariais distintos, apresenta-se como hipótese da pesquisa que a capacidade inovativa possui relação positiva com o desempenho econômico-financeiro de empresas brasileiras. A hipótese também se fundamenta nos preceitos da VBR ao buscar, em variáveis endógenas, capazes de tornar as empresas distintas entre si, a explicação para um melhor desempenho potencializando, portanto, a manutenção e/ou geração de competitividade por meio de recursos indisponíveis para os seus concorrentes.

Dessa forma, o estudo tem o objetivo de analisar a relação entre a capacidade inovativa e o desempenho econômico-financeiro de empresas brasileiras, buscando contribuir para o aprofundamento da discussão sobre os temas inovação e desempenho organizacional, a partir da compreensão sobre os componentes resultantes do processo de inovação de uma empresa (capacidade inovativa), derivados de investimentos em inovação, que podem ser considerados estratégicos para a melhoria do desempenho empresarial, nas suas dimensões econômica, operacional e de valor.

REAd | Porto Alegre - Edição 81 - N 2 - maio/agosto 2014 - p. 269-299 
Kléber Formiga Miranda, Alessandra Carvalho de Vasconcelos, Márcia Martins Mendes de Luca \& José Ednilson de Oliveira Cabral

$\mathrm{Na}$ presente pesquisa, a abrangência do termo empresas inovadoras consiste nas empresas de capital aberto enquadradas nas atividades econômicas consideradas pelo Índice Brasil de Inovação (IBI) como intensivas em pesquisa e desenvolvimento (P\&D).

Acredita-se na contribuição desta pesquisa para a discussão sobre fatores impactantes na performance das empresas, ao se examinar se a capacidade inovativa as torna competitivas por meio da influência nos seus desempenhos empresariais.

\section{REVISÃO DE LITERATURA}

\subsection{Visão Baseada em Recursos}

O contexto empresarial competitivo, marcado pela necessidade de permanente inovação e agravado pela internacionalização dos mercados, possui um objetivo básico: a continuidade da empresa. Em seu processo contínuo, as empresas podem sofrer influência do ambiente e se modificarem por meio dessa interação, contudo podem, internamente, promover diferenciação, novidade e destaque frente à concorrência. Nessa visão, voltada para o interior da firma, o ritmo de novidades e diversificação são impulsionados, impactando diretamente na competitividade entre as empresas. Essa dinâmica endógena embasou o pensamento denominado Visão Baseada em Recursos (VBR).

A VBR constitui um arcabouço teórico que busca a compreensão da vantagem competitiva sustentável no longo prazo (WERNERFELT, 1984; BARNEY, 1991; PETERAF, 1993; TEECE; PISANO; SHUEN, 1997; PENROSE, 1959). Essa perspectiva centra-se na organização interna das empresas, e assim é um complemento para a tradicional ênfase da estratégia na estrutura da firma. Penrose (2006) diz que, obedecidos os limites estabelecidos pelos ritmos possíveis de adaptações e ajustamento da estrutura administrativa das firmas a crescentes escalas de atividades, nada impedirá a indefinida expansão de suas atividades.

Para Teece, Pisano e Shuen (1997), a abordagem da VBR permite visualizar a firma como um sistema superior, cujas estruturas são rentáveis por acarretar custos consideravelmente mais baixos e com mais qualidade e desempenho dos seus produtos, residindo sua vantagem competitiva nos recursos idiossincráticos e difíceis de imitar por outras firmas.

As pesquisas que utilizam a VBR apresentam abordagens diferentes. Segundo Rouse e Daellenbach (1999), elas devem ser realizadas para empresas concorrentes que apresentem desempenho acima da média, em que os estrategistas e acadêmicos deveriam concentrar-se na vantagem competitiva sustentável. Entretanto, os autores destacam que, nas pesquisas 
A CAPACIDADE INOVATIVA E O DESEMPENHO ECONÔMICO-FINANCEIRO DE

\section{EMPRESAS INOVADORAS BRASILEIRAS}

voltadas para a VBR, é difícil identificar a vantagem competitiva, devido à velocidade com que se difundem novas tecnologias, além do fato de grandes amostras impedirem inferências quanto aos efeitos da indústria, meio ambiente, estratégia e recursos (ROUSE; DAELLENBACH, 1999).

Presume-se, com base na conceituação da VBR, que a inovação contribui com melhorias em produtos, processos e orientações gerenciais como meio para o desenvolvimento das empresas, colaborando para a melhoria do seu desempenho com vistas à continuidade, refletido nos indicadores de lucratividade. Nas palavras de Schreiber et al (2013, p. 771), "percebe-se que a competência em organizar os recursos de forma inovadora e tomar decisões com vistas à otimização dos recursos internos propicia às organizações assumir posições mais competitivas no mercado". Contudo, não se deve conceber essa perspectiva como líquida e certa. O fato de haver inovação não necessariamente implica retorno para a empresa ou seus acionistas. Ao investir em inovação, as empresas passam a contar também com a incerteza de seus resultados.

\subsection{Inovação}

Zaltman, Duncan e Holbek (1973) definem inovação como uma ideia, uma prática ou um artefato material percebido como novo, relevante e único, adotado em determinado processo, área ou por toda a organização. Por sua vez, a terceira edição do Manual de Oslo (OECD, 2005) define inovação como a implementação de um produto novo ou significativamente melhorado, ou um processo, ou um novo método de marketing, ou um novo método organizacional nas práticas de negócios, na organização do local de trabalho ou nas relações externas.

Para Garcia e Calantone (2002), a definição da OECD (Organisation for Economic Co-operation and Development) apresenta duas distinções importantes: 1) o processo de inovação compreende o desenvolvimento tecnológico de uma invenção aliado à introdução dessa invenção no mercado por meio de sua adoção e difusão; e 2) o processo de inovação é iterativo por natureza, ou seja, a introdução de uma inovação é acompanhada pela reintrodução de uma inovação melhorada.

A diversidade de conceitos de inovação amplia o universo de possibilidades à disposição de pesquisadores, porém dificulta o gerenciamento da inovação pelas empresas (TIDD; BESSANT; PAVITT, 2008). Para fins do presente estudo, adota-se o conceito da 
Kléber Formiga Miranda, Alessandra Carvalho de Vasconcelos, Márcia Martins Mendes de Luca \& José Ednilson de Oliveira Cabral

OECD (2005), que engloba os seguintes componentes da capacidade inovativa: inovação de produto, processo, organizacional e marketing.

A primeira utilização do termo capacidade de inovar (ou capacidade inovativa, como tratado no presente estudo) ocorreu, segundo Hurley e Hult (1998), no ano de 1961, na pesquisa de Burns e Stalker: capacidade da organização para aprovar ou implementar com sucesso novas ideias, processos ou produtos com sucesso. Essa definição estabelece um marco pretérito à difusão da inovação, ou seja, primeiro a empresa analisa, viabiliza e implementa a inovação para, só então, difundi-la no mercado. Posteriormente foram apresentadas outras conceituações diferentes, como em Boehe et al (2011) - propensão das empresas à exportação conduzidas pela sua internacionalização - e Furman, Porter e Stern (2001) - criação e comercialização de produtos em velocidade superior à de captação da inovação pela concorrência.

Alinhada à definição da OECD (2005), adota-se nesta pesquisa a definição da capacidade inovativa em aderência àquela reportada nos resultados do esforço inovativo, na forma disposta por Ferreira, Marques e Barbosa (2007, p. 122), os quais consideram a capacidade inovativa "algo que integra os diversos componentes resultantes do processo de inovação de uma empresa, nomeadamente, a inovação no produto, a inovação no processo, a inovação no mercado e a inovação organizacional". Assim, a capacidade inovativa passa a ser definida, constitutivamente, como inovação de produto, inovação de processo, inovação organizacional e inovação em marketing, visando à utilização das informações disponíveis na Pintec (Pesquisa de Inovação), realizada pelo Instituto Brasileiro de Geografia e Estatística (IBGE).

O padrão tecnológico das empresas brasileiras encontra-se em fase de desenvolvimento, não tendo um modelo claramente definido (VIOTTI, 2008). O acompanhamento da inovação brasileira é realizado pelo IBGE, através da Pintec que, trienalmente, cataloga dados de empresas industriais e de serviços de alta tecnologia no intuito de conhecer as atividades inovativas desenvolvidas ao longo do tempo, tornando-se fonte de consulta para pesquisas com interesse em dados nacionais sobre inovação.

Pesquisas voltadas à caracterização do perfil inovativo das empresas brasileiras levantam traços importantes para as análises realizadas nessa pesquisa. Os reportes de Campos e Ruiz (2009) demonstram a inovação de produto como o tipo de inovação predominante nas empresas brasileiras, com grande permeabilidade nos demais setores, além de considerar o desempenho inovativo brasileiro incipiente quando comparado a outros 
A CAPACIDADE INOVATIVA E O DESEMPENHO ECONÔMICO-FINANCEIRO DE

\section{EMPRESAS INOVADORAS BRASILEIRAS}

países. Kannebley Júnior, Porto e Pazello (2004) identificam como empresas não inovadoras aquelas caracterizadas como micro ou pequenas, de capital nacional, não exportadora e independente de grupos empresariais.

Algumas pesquisas nacionais relacionaram a temática inovação com vários aspectos organizacionais, destacando-se o desempenho e/ou crescimento empresariais (FERREIRA; MARQUES; BARBOSA, 2007; MALACHIAS; MEIRELLES, 2009; BRITO; BRITO; MORGANTI, 2009; GALLON; REINA; ENSSLIN, 2010), o porte da empresa (GARCIA, 2007; GOMES; KRUGLIANSKAS, 2009a; PEREIRA et al, 2009), a internacionalização das empresas (STAL, 2010; SANTOS; VASCONCELOS; DE LUCA, 2012) e a dinâmica e/ou capacidade inovativa (FURTADO et al, 2007; MELLO et al, 2008; CUNHA; PALMA; SANTOS, 2008; GOMES; KRUGLIANSKAS, 2009b; ZIMMERMANN; CARIO; RAUEN, 2009; BOEHE et al, 2011).

A diversidade de pesquisas que relacionam inovação com desempenho pode ser atribuída à busca pelo entendimento de como se manter ativamente no mercado, de se buscar uma gestão ótima das inovações e/ou de reduzir o risco de investimentos direcionados a tal fim. Resumidamente, as empresas inovam procurando manter sua vantagem competitiva. Em outras palavras, em função das características do atual ambiente de negócios, Brito e Cândido (2003, p. 5) informam que "a busca e a prática da inovação passa a ser uma necessidade imprescindível para que as organizações possam encontrar os mecanismos mais adequados para conduzir as suas operações e, principalmente formular e implementar suas estratégias".

Em consonância com Ferreira, Marques e Barbosa (2007), Malachias e Meirelles (2009), Brito, Brito e Morganti (2009) e Gallon, Reina e Ensslin (2010), esta pesquisa relaciona inovação e desempenho empresarial levando em conta a inovação compreendida no conceito de capacidade inovativa e o desempenho empresarial nas perspectivas econômica, operacional e de valor.

\subsection{Desempenho}

Segundo Buchanan e Huczynski (2004), o conceito de desempenho implica em verificar níveis de eficiência e eficácia, boa ou má performance, utilizando-se de uma série de indicadores desde os tradicionais indicadores econômico-financeiros até medidas de desempenho social, dentre outras. A necessidade de se tomar decisões nos diversos níveis empresariais em busca da continuidade da empresa passa, conforme Assaf Neto (2008), pelas informações viabilizadas pela contabilidade, comportamento de mercado e desempenho 
Kléber Formiga Miranda, Alessandra Carvalho de Vasconcelos, Márcia Martins Mendes de Luca \& José Ednilson de Oliveira Cabral

interno da empresa. Destarte, os stakeholders utilizam indicadores de desempenho como forma de compreensão dos resultados empresariais.

A mensuração do desempenho empresarial, nesta pesquisa, direciona-se pela análise de três indicadores, quais sejam os desempenhos econômico, operacional e de valor. Sob o enfoque contábil da avaliação do desempenho organizacional, Matarazzo (2010) afirma que as demonstrações financeiras, seguindo normas contábeis, fornecem dados sobre as empresas. A clareza e a objetividade dispensadas na geração dos dados permitirão que o analista venha a gerar seus relatórios sobre situações e cenários diversos. Uma das formas básicas de medir esse desempenho se dá pela relação entre as vendas e o custo, resultando no que se costuma chamar de lucro, seja ele contábil ou econômico.

O lucro contábil é constituído de valores resultantes das demonstrações contábeis, enquanto o lucro econômico é medido pelo valor econômico da empresa, ou seja, sofre influência do seu valor no mercado. Chan (2006) menciona a atenção dedicada pelos analistas de mercado e investidores no lucro reportado pelas empresas, demonstrando ser uma fonte importante de informação para o processo de tomada de decisão.

Inerente ao desempenho empresarial também está o conceito de criação de valor pelas empresas. Copeland, Koller e Murrin (2002) enfatizam que a maximização do valor para o acionista deve se sobrepor à continuidade da empresa, e que, na maioria dos países desenvolvidos, a influência dos acionistas domina os interesses da alta administração, suscitando um melhor desempenho das companhias voltadas para o acionista.

O valor atribuído a uma empresa se dá por meio de previsões futuras, tratando-se de uma estimativa e passível, portanto, de margem de erro. Indicadores de desempenho, com base na geração de valor, refletem o sucesso da empresa em suas decisões financeiras, pois se uma empresa vale mais do que o capital nela investido, então ela terá criado riqueza (ARAÚJO; ASSAF NETO, 2003).

Considerando-se o objetivo da presente pesquisa e para representar os conceitos de desempenho pela ótica do lucro, abordando a rentabilidade das empresas; pela ótica do desempenho operacional, com a apresentação de indicador voltado para apresentar um panorama da geração operacional de caixa; e pela ótica do valor, por meio de indicador que se utilize valores de mercado e contábil em sua composição; são utilizados os indicadores ROA (Return on Assets), Ebitda (Earnings Before Interest, Taxes, Depreciation and Amortization) e MVA $^{\circledR}$ (Market Value Added). Esclarece-se não ser pretensão exaurir a análise do desempenho empresarial em seu sentido amplo. A escolha dos indicadores considerou a 
A CAPACIDADE INOVATIVA E O DESEMPENHO ECONÔMICO-FINANCEIRO DE

\section{EMPRESAS INOVADORAS BRASILEIRAS}

contribuição para verificar a relação entre a inovação e o desempenho nos três aspectos mencionados.

Campos e Ruiz (2009) afirmam que não se deve negligenciar a diversidade setorial nas pesquisas relacionadas à inovação. Além disso, deve-se levar em conta o porte das empresas (GARCIA, 2007; GOMES; KRUGLIANSKAS, 2009a; PEREIRA et al, 2009; CAMPOS; RUIZ, 2009). Destarte, esta pesquisa tem como unidade de análise empresas de capital aberto enquadradas nas atividades econômicas consideradas inovadoras pelo Índice Brasil de Inovação (IBI), levando em conta o que preconiza a VBR, no pressuposto de que a capacidade inovativa constitua fonte de melhoria do desempenho das empresas, com reflexo na geração de vantagem competitiva.

Diante do exposto, a análise da hipótese da pesquisa - a capacidade inovativa possui relação positiva com o desempenho econômico-financeiro de empresas brasileiras - considera os três indicadores de desempenho separadamente, ROA, Ebitda e MVA ${ }^{\circledR}$, de modo a testar as hipóteses operacionais:

$\mathrm{H}_{1}$ - a capacidade inovativa de empresas brasileiras apresenta relação positiva com o desempenho econômico.

$\mathrm{H}_{2}$ - a capacidade inovativa de empresas brasileiras apresenta relação positiva com o desempenho operacional.

$\mathrm{H}_{3}$ - a capacidade inovativa de empresas brasileiras apresenta relação positiva com a correspondente geração de valor.

\section{MÉTODO DE PESQUISA}

\subsection{Classificação da pesquisa}

Esta pesquisa busca conhecer as características da inovação, especificamente a capacidade inovativa, relacionando-a com o desempenho econômico-financeiro das empresas estudadas, caracterizando-se, assim, como exploratória e descritiva, segundo o conceito de Richardson (2009). A utilização de métodos e técnicas estatísticos para interpretação dos resultados, aliada ao controle do delineamento, confirma a sua natureza quantitativa, conforme dispõe Roesch (2006).

Utiliza técnicas estatísticas de correlação e regressão linear, considerando que ambas “compreendem a análise de dados amostrais para obter informações sobre se duas ou mais variáveis são relacionadas e qual a natureza desse relacionamento" (CUNHA; COELHO, 2009, p. 132). As regressões são analisadas por meio de dados em painel, pois, segundo Stock 
Kléber Formiga Miranda, Alessandra Carvalho de Vasconcelos, Márcia Martins Mendes de Luca \& José Ednilson de Oliveira Cabral

e Watson (2004) e Cameron e Trivedi (2005), os processos de estimação baseados em dados em painel são bem atraentes, pois possibilitam análises mais complexas e eficientes dos modelos econométricos. Entretanto, a análise torna-se bem mais complexa, devido às diferenças nas formas estruturais entre os mais diversos tipos de agente econômico.

\subsection{Amostra e variáveis}

Levando em conta o que preconiza a VBR, no pressuposto de que a capacidade inovativa se constitui em recurso diferenciador entre as empresas, refletindo-se na melhoria dos seus desempenhos e consequente geração de vantagem competitiva, analisou-se 174 empresas de capital aberto, listadas na BM\&FBovespa, todas classificadas em setores considerados pelo IBI como intensivos em P\&D e, portanto, tidas como inovadoras. A escolha recaiu em empresas que atendessem simultaneamente aos seguintes pré-requisitos: a) ser de capital aberto; e b) ser classificada em um dos setores/segmentos abrangidos pelos critérios do IBI. O processo de escolha obedeceu ao cruzamento entre a classificação nacional de atividades econômicas (CNAE) constante da tabela do IBI e a classificação de segmentos (ou subsetores) disponibilizada pela BM\&FBovespa.

Para a amostra da pesquisa, caracterizada como intencional (RICHARDSON, 2009), foram estabelecidas as seguintes características: a disponibilidade das variáveis de desempenho empresarial (econômico, operacional e de valor) no banco de dados Economática $^{\circledR}$ nos períodos de 2006 e 2009 e das variáveis de inovação na base de dados das PINTECs de 2005 e 2008. Encaminhada ao IBGE, a listagem das 174 empresas resultou em uma amostra de 73 empresas, cujos dados foram criptografados, por exigência legal, para garantir o caráter confidencial às informações utilizadas nas pesquisas do IBGE.

Cabe destacar que o lapso temporal entre os dados coletados e o desenvolvimento da pesquisa se deve ao fator referente ao acesso aos dados junto ao IBGE, além do fato de que a Pintec é realizada trienalmente. Durante o processo de coleta dos dados, estavam disponíveis apenas os dados da Pintec 2005 e 2008. A Pintec 2011 foi divulgada em dezembro de 2013, após a coleta dos dados.

O Quadro 1 apresenta as variáveis dependentes e independentes da pesquisa. As variáveis de desempenho são dispostas com suas respectivas nomenclaturas e fórmulas. Quanto às de inovação, demonstra-se a composição da capacidade inovativa com os dados obtidos no dicionário de variáveis fornecido pelo IBGE, baseado no questionário aplicado pela Pintec 2008. São apresentadas as nomenclaturas de cada variável com suas respectivas fórmulas e escala. As variáveis componentes de cada tipo de inovação são constituídas de 
A CAPACIDADE INOVATIVA E O DESEMPENHO ECONÔMICO-FINANCEIRO DE

\section{EMPRESAS INOVADORAS BRASILEIRAS}

variáveis dicotômicas, sendo, portanto, atribuído um valor para cada uma delas. O total dos valores atribuídos constituiu o valor de cada tipo de inovação (produto, processo, organizacional e marketing) e da capacidade inovativa total (somatório de todos os valores).

Para compor o valor da capacidade inovativa, variável endógena indicadora de recurso de diferenciação entre as empresas nos preceitos da VBR, utilizaram-se os dados disponíveis para cada uma das variáveis nos dois anos analisados nesta pesquisa. O dicionário de variáveis dispunha de dados em quantidade superior àquela utilizada nesta pesquisa, devido às dissonâncias entre a proposta da variável e os objetivos da pesquisa. Para inovação de produto e de processo, utilizaram-se os dados correspondentes às informações qualitativas desses tipos de inovação, e excluíram-se as variáveis relacionadas com a autoria e a localização da inovação, totalizando seis variáveis a serem analisadas: três de inovação de produto e três de inovação de processo.

Das informações relacionadas à inovação organizacional e à inovação de marketing, foram utilizadas duas variáveis para cada tipo de inovação, por serem as únicas presentes nas duas citadas edições da Pintec. Assim, a definição das variáveis relacionadas à capacidade inovativa obedeceu ao critério da objetividade das respostas.

Quadro 1 - Variáveis da pesquisa

\begin{tabular}{|c|c|c|c|}
\hline Variável & Nomenclatura & Fórmula & Escala \\
\hline $\begin{array}{l}\text { Desempenho } \\
\text { econômico }\end{array}$ & ROA & Lucro Operacional / Ativo Total & $*$ \\
\hline $\begin{array}{l}\text { Desempenho } \\
\text { operacional }\end{array}$ & EBITDA & Ebitda / Ativo Total & $*$ \\
\hline $\begin{array}{l}\text { Desempenho } \\
\text { de valor }\end{array}$ & $\mathrm{MVA}^{\circledR}$ & $\begin{array}{c}\text { (Valor de Mercado - Patrimônio Líquido Contábil) / } \\
\text { Ativo Total }\end{array}$ & $*$ \\
\hline Prod 1 & PROD_NOVO_EMP & $\begin{array}{l}\text { Atribuído o valor } 1 \text { quando a empresa introduziu } \\
\text { produto novo ou significativamente aperfeiçoado, } \\
\text { mas já ofertado pela concorrência. Caso contrário, } \\
\text { atribuído } 0 \text {. }\end{array}$ & 0 a 1 \\
\hline Prod2 & PROD_NOVO_BR & $\begin{array}{l}\text { Atribuído o valor } 1 \text { quando a empresa introduziu } \\
\text { produto novo ou significativamente aperfeiçoado no } \\
\text { mercado nacional. Caso contrário, atribuído } 0 \text {. }\end{array}$ & 0 a 1 \\
\hline Prod3 & PRINC_PROD & $\begin{array}{c}\text { Atribuído o valor } 1 \text { quando o principal produto é } \\
\text { aprimorado de um já existente e o valor } 2 \text { quando } \\
\text { completamente novo para a empresa. }\end{array}$ & 0 a 2 \\
\hline Proc 1 & PROC_NOVO_EMP & $\begin{array}{c}\text { Atribuído o valor } 1 \text { quando pelo menos uma inovação } \\
\text { de processo introduzida já existia no setor no Brasil. } \\
\text { Caso contrário, atribuído } 0 .\end{array}$ & 0 a 1 \\
\hline Proc2 & PROC_NOVO_BR & $\begin{array}{c}\text { Atribuído o valor } 1 \text { quando pelo menos uma inovação } \\
\text { de processo introduzida era nova para o setor no } \\
\text { Brasil. Caso contrário, atribuído } 0 .\end{array}$ & 0 a 1 \\
\hline Proc3 & PRINC_PROC & $\begin{array}{l}\text { Atribuído o valor } 1 \text { quando o principal processo é } \\
\text { aprimoramento de um já existente e o valor } 2 \text { quando } \\
\text { complemente novo para a empresa. }\end{array}$ & 0 a 2 \\
\hline Org1 & NOVA_TEC_GEST & $\begin{array}{l}\text { Atribuído o valor } 1 \text { quando a empresa implementou } \\
\text { novas técnicas de gestão para melhorar rotinas e } \\
\text { práticas de trabalho, assim como o uso interno da }\end{array}$ & 0 a 1 \\
\hline
\end{tabular}

REAd | Porto Alegre - Edição 81 - N 2 - maio/agosto 2014 - p. 269-299 
Kléber Formiga Miranda, Alessandra Carvalho de Vasconcelos, Márcia Martins Mendes de Luca \& José Ednilson de Oliveira Cabral

\begin{tabular}{|c|c|c|c|}
\hline & & $\begin{array}{l}\text { troca de informações, de conhecimento e habilidades. } \\
\text { Caso contrário, atribuído } 0 .\end{array}$ & \\
\hline Org2 & DIST_RESP_DEC & $\begin{array}{l}\text { Atribuído o valor } 1 \text { quando a empresa implementou } \\
\text { novos métodos de organização do trabalho para } \\
\text { melhor distribuir responsabilidades e poder de } \\
\text { decisão. Caso contrário, atribuído } 0 .\end{array}$ & 0 a 1 \\
\hline Mkt1 & CONCEITO_MKT & $\begin{array}{c}\text { Atribuído o valor } 1 \text { quando a empresa realizou } \\
\text { significativas mudanças nos conceitos/estratégias de } \\
\text { marketing. Caso contrário, atribuído } 0 \text {. }\end{array}$ & 0 a 1 \\
\hline Mkt2 & NOVO_DESIGN & $\begin{array}{l}\text { Atribuído o valor } 1 \text { quando, em pelo menos um dos } \\
\text { produtos, a empresa realizou significativas mudanças } \\
\text { na estética e no desenho, ou outras mudanças } \\
\text { subjetivas. Caso contrário, atribuído } 0 \text {. }\end{array}$ & 0 a 1 \\
\hline $\begin{array}{l}\text { Inovação de } \\
\text { produto }\end{array}$ & INPROD & $\begin{array}{c}\text { PROD_NOVO_EMP + PROD_NOVO_BR + } \\
\text { PRINC_PROD }\end{array}$ & 0 a 4 \\
\hline $\begin{array}{l}\text { Inovação de } \\
\text { processo }\end{array}$ & INPROC & $\begin{array}{c}\text { PROC_NOVO_EMP + PROC_NOVO_BR + } \\
\text { PRINC_PROC }\end{array}$ & 0 a 4 \\
\hline $\begin{array}{l}\text { Inovação } \\
\text { organizacional }\end{array}$ & INORG & NOVA_TEC_GEST + DIST_RESP_DEC & 0 a 2 \\
\hline $\begin{array}{l}\text { Inovação de } \\
\text { marketing }\end{array}$ & INMKT & CONCEITO_MKT + NOVO_DESIGN & 0 a 2 \\
\hline $\begin{array}{l}\text { Capacidade } \\
\text { inovativa }\end{array}$ & CAPINOV & INPROD + INPROC + INORG + INMKT & 0 a 12 \\
\hline
\end{tabular}

Fonte: Elaborado pelos autores com base no dicionário de variáveis da Pintec 2008, a partir de IBGE (2009).

A pontuação atribuída a cada variável observou o seguinte critério: se a resposta fosse "não", seria atribuída valor 0; se a resposta fosse "sim", atribuir-se-ia valor 1. Para as variáveis Prod3 e Proc3 foi atribuída o valor 1 se a resposta indicasse uma inovação aprimorada de uma já existente; e o valor 2 se a resposta indicasse uma inovação completamente nova para a empresa. Dessa forma, receberiam valores menores as empresas que não praticassem algum tipo de inovação analisado ou utilizassem conhecimentos já existentes na empresa, em vez de novos conhecimentos.

Quanto aos indicadores de desempenho, ressalta-se a divisão das variáveis Ebitda e MVA $^{\circledR}$ pelo Ativo Total, para padronização dos dados e consequente melhoria do processo de estimação dos coeficientes das regressões.

De acordo com a OECD (2005, p. 148), o Manual de Oslo orienta que "a dimensão do período de observação para as pesquisas sobre inovação não exceda três anos e não seja menor que um ano". Considerando-se que os dados das PINTECs adotam a referência temporal de três anos para variáveis qualitativas (inovação de produto, de processo, organizacional e em marketing), optou-se por coletar os dados necessários à análise do desempenho econômico-financeiro um ano após cada pesquisa. Assim, os dados da Pintec de 2005 foram relacionados com os indicadores de desempenho das empresas de 2006, enquanto os dados da Pintec de 2008 foram relacionados com o desempenho de 2009. Cozzarin (2004) 
A CAPACIDADE INOVATIVA E O DESEMPENHO ECONÔMICO-FINANCEIRO DE

\section{EMPRESAS INOVADORAS BRASILEIRAS}

e Santos (2009) também verificaram ou consideraram que o impacto da inovação ocorre um ano após o período do investimento correspondente.

Para complemento da análise das relações entre variáveis de inovação (capacidade inovativa) e de desempenho empresarial, foram realizadas análises adicionais; ou seja, além da análise da relação direta entre as variáveis, houve um desmembramento da variável independente, para ampliação da análise de causalidade entre as variáveis.

A análise das hipóteses da pesquisa foi realizada por meio das variáveis dependentes ROA, Ebitda e $\mathrm{MVA}^{\circledR}$, relacionadas, separadamente, com a variável CAPINOV em suas formas individual e consolidada. A aceitação das hipóteses condicionou-se à verificação de consonância com as abordagens da VBR sobre estratégias de diferenciação empresarial. Assim, foram aceitas aquelas em que a capacidade inovativa, composta por variáveis de inovação geradoras de diferenciação entre as empresas, apresentou relação positiva e significante com as três variáveis de desempenho empresarial.

\subsection{Procedimentos da pesquisa}

A Figura 1 apresenta o design da pesquisa para contribuir com a visualização holística dos procedimentos utilizados.

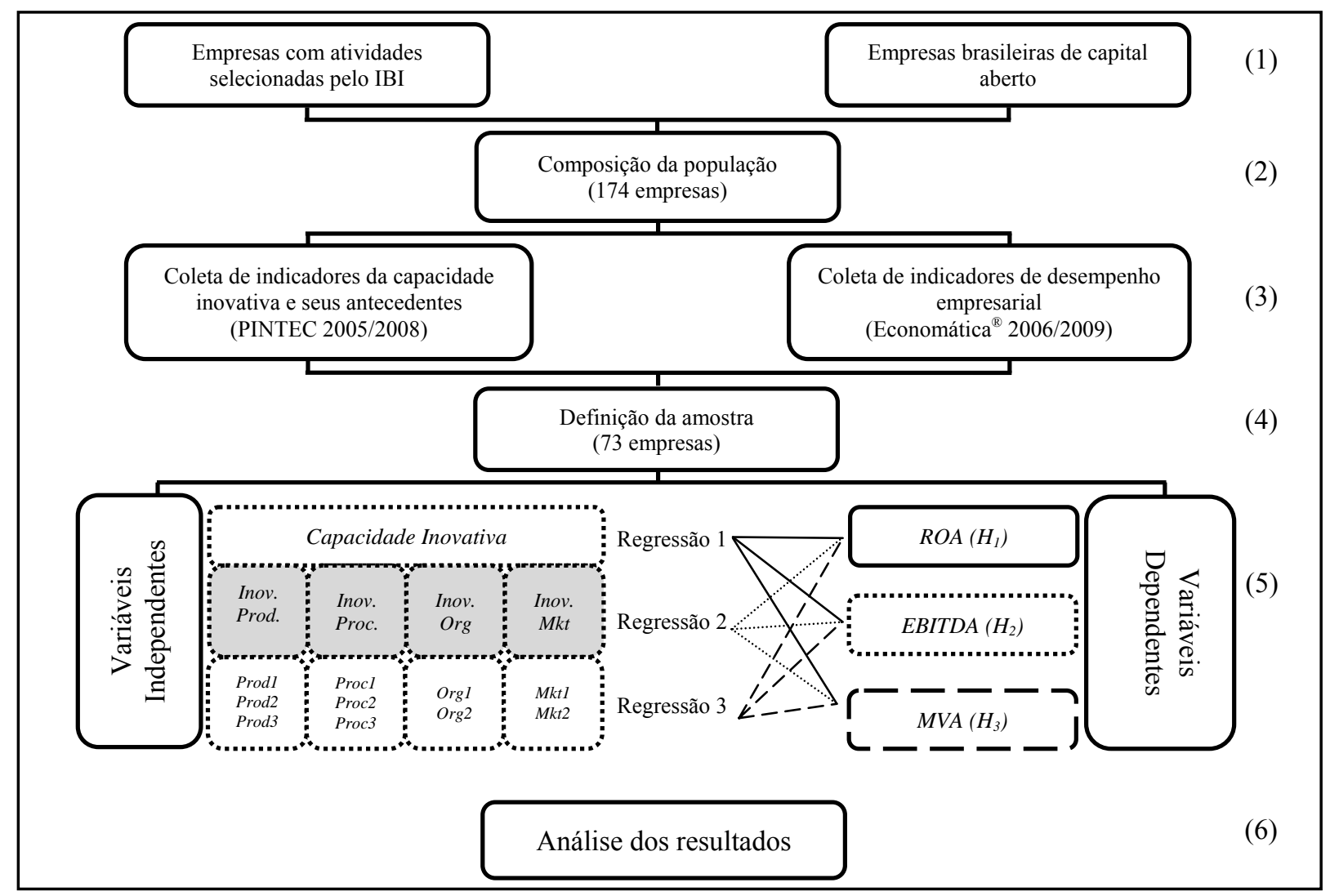

Figura 1 - Design da Pesquisa

Fonte: Elaborado pelos autores

REAd | Porto Alegre - Edição 81 - N 2 - maio/agosto 2014 - p. 269-299 
Kléber Formiga Miranda, Alessandra Carvalho de Vasconcelos, Márcia Martins Mendes de Luca \& José Ednilson de Oliveira Cabral

De acordo com a Figura 1, os procedimentos metodológicos da pesquisa compreenderam seis etapas, em que: (1) corresponde aos critérios utilizados para escolha da população; (2) aplicação dos critérios para escolha da população, resultando em 174 empresas; (3) coleta das informações, junto à Pintec, referente aos dados de 2005 e 2008, sobre capacidade inovativa e seus antecedentes; e, junto à base de dados do Economática ${ }^{\circledR}$, referente aos dados de 2006 e 2009, sobre desempenho empresarial; (4) definição da amostra por meio da disponibilidade de dados nos períodos indicados para cada base de dados, reunindo 73 empresas; (5) representação das variáveis dependentes e independentes componentes das correlações e regressões lineares já descritas, com suas respectivas hipóteses; e (6) análise dos resultados através de relatório emitido pelo aplicativo Stata: Data Analysis and Statistical Software, indicado pelo IBGE.

Ressalta-se a impossibilidade de inferências individuais quanto às empresas da amostra. Concluída a fase de geração das análises de correlação e das regressões, os relatórios emitidos pelo aplicativo estatístico passaram pela análise do Comitê de Sigilo do IBGE para averiguação de possíveis dados identificadores. Somente quando os resultados foram considerados íntegros, os relatórios foram liberados e foi iniciada a análise de resultados.

\section{RESULTADOS DA PESQUISA}

As análises realizadas no banco de dados formado pela concatenação das variáveis de desempenho econômico-financeiro encaminhadas ao IBGE com as variáveis de inovação da Pintec geraram as estatísticas descritivas apresentadas na Tabela 1.

Tabela 1 - Estatística descritiva das variáveis componentes das principais regressões da pesquisa

\begin{tabular}{l|c|c|c|c}
\hline \multirow{2}{*}{ Idem } & Capacidade Inovativa & \multicolumn{3}{|c}{ Variável de Desempenho Empresarial } \\
\cline { 2 - 5 } & CAPINOV & ROA & EBITDA & MVA $^{(B)}$ \\
\hline Média & 4,61 & 0,10 & 0,13 & 0,44 \\
Desvio-padrão & 2,73 & 0,08 & 0,09 & 0,75 \\
\hline
\end{tabular}

Fonte: Elaborado pelos autores.

Ressalte-se que os valores máximos, assim como os valores mínimos, não foram informados, como forma de se evitar a identificação das empresas. Assim, os dados da Tabela 1 evidenciam o valor médio 4,61 para a variável CAPINOV (valor máximo: 12). Significa dizer que a capacidade inovativa média é inferior à metade do total, embora o alto índice da variância indique que algumas empresas possuem valores nos dois extremos.

REAd | Porto Alegre - Edição 81 - N 2 - maio/agosto 2014 - p. 269-299 
A CAPACIDADE INOVATIVA E O DESEMPENHO ECONÔMICO-FINANCEIRO DE

\section{EMPRESAS INOVADORAS BRASILEIRAS}

As variáveis de desempenho empresarial apresentaram valor médio abaixo de 1, justificado pela normalização do Ebitda e do $\mathrm{MVA}^{\circledR}$ com o Ativo Total e o ROA, por se tratar de um índice. De acordo com a literatura, os coeficientes de análises que relacionam índices com valores lineares não apresentam elasticidade. Gujarati (2006, p. 146) sugere a fórmula “[antilog $(\beta)-1]^{*} 100$ ” para o cálculo das elasticidades dos coeficientes, a ser utilizada nas análises das regressões.

Realizados os procedimentos de análise e tratamento dos dados, iniciou-se o processo de geração de matrizes de correlação e regressões lineares. A capacidade inovativa, já apresentada de forma consolidada, foi desmembrada, e suas variáveis componentes foram analisadas individualmente e em subgrupos representantes da inovação de produto, de processo, organizacional e de marketing.

A seguir, são apresentadas as análises de cada uma das hipóteses correspondentes aos indicadores de desempenho adotados na pesquisa. Inicialmente, analisa-se o ROA $\left(\mathrm{H}_{1}\right)$, seguindo-se o Ebitda $\left(\mathrm{H}_{2}\right)$ e o $\mathrm{MVA}^{\circledR}\left(\mathrm{H}_{3}\right)$. Antes de se aplicar as regressões nas equações, aplicou-se o teste de Hausman, que indicou o modelo por efeitos fixos como o mais indicado na análise, embora as análises do $\mathrm{MVA}^{\circledR}\left(\mathrm{H}_{3}\right)$ tenham sido realizadas pelo modelo de efeitos aleatórios, por apresentar coeficientes significantes.

\subsection{Relação entre a capacidade inovativa e o ROA}

Apresenta-se, a seguir, a relação entre o indicador de desempenho econômico ROA e a capacidade inovativa, através da análise de correlação e, posteriormente, de regressões lineares. A Tabela 2 mostra os graus da matriz de correlação entre as variáveis.

Tabela 2 - Graus de correlação entre a capacidade inovativa e o ROA

\begin{tabular}{c|c|c|c|c|c|c|c|c|c|c|c|c|c|c|c}
\hline Variável & \multicolumn{10}{c}{ Variável Independente } \\
\cline { 2 - 14 } Dependente & $(1)$ & $(2)$ & $(3)$ & $(4)$ & $(5)$ & $(6)$ & $(7)$ & $(8)$ & $(9)$ & $(10)$ & $(11)$ & $(12)$ & $(13)$ & $(14)$ & $(15)$ \\
\hline ROA & 0,07 & 0,05 & 0,17 & 0,07 & 0,14 & $-0,01$ & 0,18 & 0,02 & 0,10 & 0,02 & $-0,04$ & $-0,01$ & $-0,02$ & $-0,06$ & $-0,04$ \\
\hline
\end{tabular}

Nota: (1) CAPINOV, (2) PROD_NOVO_EMP, (3) PROD_NOVO_BR, (4) PRINC_PROD, (5) INPROD, (6)

PROC_NOVO_EMP, (7) PROC_NOVO_BR, (8) PRINC_PROC, (9) INPROC, (10) NOVA_TEC_GEST, (11)

DIST_RESP_DEC, (12) INORG, (13) CONCEITO_MKT, (14) NOVO_DESIGN e (15) INMKT.

Fonte: Elaborado pelos autores.

Os dados dispostos na Tabela 2 demonstram situações antagônicas entre as variáveis, devido à distribuição dos valores entre positivos e negativos. O grau de correlação das variáveis de inovação de produto contribuiu para a relação causal dessas variáveis com o 
Kléber Formiga Miranda, Alessandra Carvalho de Vasconcelos, Márcia Martins Mendes de Luca \& José Ednilson de Oliveira Cabral

ROA. Entretanto, o mesmo não acontece com a inovação em marketing, por possuir baixo grau de correlação e influenciar o ROA negativamente. Assim, o ROA seria ampliado ao se inovar em produto. Entretanto, se forem implementadas novas estratégias ou conceitos de marketing, por exemplo, o ROA tenderia para baixo.

A Tabela 3 apresenta os resultados obtidos pela aplicação das regressões entre o ROA e as variáveis componentes da capacidade inovativa.

Tabela 3 - Regressões para $\mathrm{H}_{1}-\mathrm{ROA}$

\begin{tabular}{|c|c|c|c|c|}
\hline \multicolumn{5}{|c|}{ Regressão da Hipótese 1} \\
\hline \multicolumn{5}{|l|}{0,0375} \\
\hline $\mathrm{ROA}$ & Coef. & Std. Err. & $\mathrm{t}$ & $\mathrm{P}>|\mathrm{z}|$ \\
\hline CAPINOV & $-0,0040224$ & 0,0032853 & $-1,22$ & 0,225 \\
\hline cons & 0,1162611 & 0,0151441 & 7,68 & 0,000 \\
\hline \multicolumn{5}{|c|}{ Regressão Complementar (variáveis da capacidade inovativa) } \\
\hline \multicolumn{5}{|l|}{$\mathrm{R}^{2}: \quad 0,0000$} \\
\hline $\mathrm{ROA}$ & Coef. & Std. Err. & $\mathrm{T}$ & $\mathrm{P}>|\mathrm{z}|$ \\
\hline INPROD & $0,0170314^{*}$ & 0,0093622 & 1,82 & 0,073 \\
\hline INPROC & $-0,0051487$ & 0,0093523 & $-0,55$ & 0,584 \\
\hline INORG & $-0,0100821$ & 0,0111588 & $-0,90$ & 0,369 \\
\hline INMKT & $-0,0213812^{* *}$ & 0,0103931 & $-2,06$ & 0,043 \\
\hline cons & 0,1152095 & 0,0150648 & 7,65 & 0,000 \\
\hline \multicolumn{5}{|c|}{ Regressão Complementar (variáveis individuais da capacidade inovativa) } \\
\hline $\mathrm{R}^{2}: \quad 0,0031$ & & & & \\
\hline $\mathrm{ROA}$ & Coef. & Std. Err. & $\mathrm{T}$ & $\mathrm{P}>|\mathrm{z}|$ \\
\hline PROD_NOVO_EMP & $-0,0185018$ & 0,0248620 & $-0,74$ & 0,459 \\
\hline PROD_NOVO_BR & $0,0353984 * *$ & 0,0157287 & 2,25 & 0,027 \\
\hline PRINC_PROD & $0,0377949 * *$ & 0,0187229 & 2,02 & 0,047 \\
\hline PROC_NOVO_EMP & $-0,0221213$ & 0,0216425 & $-1,02$ & 0,310 \\
\hline PROC_NOVO_BR & $-0,0097865$ & 0,0222452 & $-0,44$ & 0,661 \\
\hline PRINC_PROC & $-0,0073681$ & 0,0215003 & $-0,34$ & 0,733 \\
\hline NOVA_TEC_GEST & 0,0290377 & 0,0251910 & 1,15 & 0,253 \\
\hline DIST_RESP_DEC & $-0,0371192$ & 0,0243123 & $-1,53$ & 0,131 \\
\hline CONCEITO_MKT & $-0,0051094$ & 0,0235371 & $-0,22$ & 0,829 \\
\hline NOVO_DESIGN & $-0,0320722$ & 0,0269991 & $-1,19$ & 0,239 \\
\hline cons & 0,1191989 & 0,0195822 & 6,09 & 0,000 \\
\hline
\end{tabular}

Nota: Significante: $* 10 \%$ e $* * 5 \%$.

Fonte: Elaborado pelos autores.

REAd | Porto Alegre - Edição 81 - N 2 - maio/agosto 2014 - p. 269-299 
A CAPACIDADE INOVATIVA E O DESEMPENHO ECONÔMICO-FINANCEIRO DE

\section{EMPRESAS INOVADORAS BRASILEIRAS}

Os resultados evidenciados na Tabela 3 demonstram não haver relação significante entre o ROA e a capacidade inovativa, rejeitando-se $\mathrm{H}_{1}$. Esse resultado foi impulsionado pelas relações negativas apresentadas pelas variáveis de inovação organizacional e em marketing, já mencionadas na análise da correlação. A relação negativa entre as variáveis de inovação de processo sofreu influência dos graus negativos apresentados.

As relações positivas identificadas na análise individualizada das variáveis de capacidade inovativa indicaram o aumento do ROA quando a empresa inova em produtos novos ou significativamente aperfeiçoados para o mercado nacional e quando seu principal produto é completamente novo para a empresa. Esse resultado contribuiu para a relação positiva entre o indicador econômico (ROA) e a inovação de produto (INPROD), indicando a afinidade das empresas nesse tipo de inovação. Os resultados são diferentes quando se inova em marketing, pois a variável consolidada (INMKT) apresentou relação negativa com o ROA.

\subsection{Relação entre a capacidade inovativa e o Ebitda}

Neste tópico relaciona-se o indicador operacional Ebitda com a capacidade inovativa, iniciando-se pela análise de correlação e pela regressão linear. A Tabela 4 identifica os graus de correlação entre as variáveis ora analisadas.

Tabela 4 - Graus de correlação entre a capacidade inovativa e o Ebitda

\begin{tabular}{|c|c|c|c|c|c|c|c|c|c|c|c|c|c|c|c|}
\hline \multirow{2}{*}{$\begin{array}{c}\text { Variável } \\
\text { Dependente }\end{array}$} & \multicolumn{15}{|c|}{ Variável Independente } \\
\hline & (1) & (2) & (3) & (4) & $(5)$ & (6) & (7) & (8) & (9) & (10) & (11) & (12) & (13) & (14) & (15) \\
\hline EBITDA & 0,07 & 0,07 & 0,19 & 0,04 & 0,15 & $-0,04$ & 0,23 & 0,01 & 0,10 & 0,00 & $-0,03$ & $-0,01$ & $-0,01$ & $-0,06$ & $-0,04$ \\
\hline
\end{tabular}

Nota: (1) CAPINOV, (2) PROD_NOVO_EMP, (3) PROD_NOVO_BR, (4) PRINC_PROD, (5) INPROD, (6) PROC_NOVO_EMP, (7) PROC_NOVO_BR, (8) PRINC_PROC, (9) INPROC, (10) NOVA_TEC_GEST, (11) DIST_RESP_DEC, (12) INORG, (13) CONCEITO_MKT, (14) NOVO_DESIGN e (15) INMKT.

Fonte: Elaborado pelos autores.

Similarmente ao ROA, o indicador operacional Ebitda apresenta graus de correlação negativos e positivos com a capacidade inovativa. Destaque-se, novamente, a contribuição da variável CAPINOV e de todas as variáveis da inovação de produto, por apresentarem relação positiva, devendo influenciar a relação positiva com o desempenho. A Tabela 5 apresenta os resultados da relação entre a capacidade inovativa e o Ebitda. 
Kléber Formiga Miranda, Alessandra Carvalho de Vasconcelos, Márcia Martins Mendes de Luca \& José Ednilson de Oliveira Cabral

Tabela 5 - Regressões para $\mathrm{H}_{2}-$ EBITDA

\begin{tabular}{|c|c|c|c|c|}
\hline \multicolumn{5}{|c|}{ Regressão da Hipótese 2} \\
\hline \multicolumn{5}{|l|}{0,0543} \\
\hline EBITDA & Coef. & Std. Err. & $\mathrm{t}$ & $\mathrm{P}>|\mathrm{z}|$ \\
\hline CAPINOV & $-0,0061942 *$ & 0,0031848 & $-1,94$ & 0,056 \\
\hline cons & 0,1636558 & 0,0146807 & 11,15 & 0,000 \\
\hline \multicolumn{5}{|c|}{ Regressão Complementar (variáveis da capacidade inovativa) } \\
\hline \multicolumn{5}{|l|}{0,0044} \\
\hline EBITDA & Coef. & Std. Err. & $\mathrm{T}$ & $\mathrm{P}>|\mathrm{z}|$ \\
\hline INPROD & 0,0149090 & 0,0096366 & 1,55 & 0,126 \\
\hline INPROC & $-0,0109677$ & 0,0085719 & $-1,28$ & 0,205 \\
\hline INORG & $-0,0097848$ & 0,0112278 & $-0,87$ & 0,386 \\
\hline INMKT & $-0,0217186^{* *}$ & 0,0107514 & $-2,02$ & 0,047 \\
\hline _cons & 0,1624723 & 0,0148408 & 10,95 & 0,000 \\
\hline \multicolumn{5}{|c|}{ Regressão Complementar (variáveis individuais da capacidade inovativa) } \\
\hline 0,0069 & & & & \\
\hline EBITDA & Coef. & Std. Err. & $\mathrm{T}$ & $\mathrm{P}>|\mathrm{z}|$ \\
\hline PROD_NOVO_EMP & $-0,0166124$ & 0,0243868 & $-0,68$ & 0,498 \\
\hline PROD_NOVO_BR & $0,0286191 *$ & 0,0166995 & 1,71 & 0,091 \\
\hline PRINC_PROD & $0,0342784 *$ & 0,0189567 & 1,81 & 0,075 \\
\hline PROC_NOVO_EMP & $-0,0375050 *$ & 0,0200648 & $-1,87$ & 0,066 \\
\hline PROC_NOVO_BR & $-0,0080461$ & 0,0217539 & $-0,37$ & 0,713 \\
\hline PRINC_PROC & $-0,0024274$ & 0,0204406 & $-0,12$ & 0,906 \\
\hline NOVA_TEC_GEST & 0,0150167 & 0,0255171 & 0,59 & 0,558 \\
\hline DIST_RESP_DEC & $-0,0296350$ & 0,0241493 & $-1,23$ & 0,224 \\
\hline CONCEITO_MKT & $-0,0006281$ & 0,0248795 & $-0,03$ & 0,980 \\
\hline NOVO_DESIGN & $-0,0368550$ & 0,0269344 & $-1,37$ & 0,175 \\
\hline _cons & 0,1702295 & 0,0190138 & 8,95 & 0,000 \\
\hline
\end{tabular}

Fonte: Elaborado pelos autores.

A análise dos resultados expostos na Tabela 5 sugere uma relação negativa entre o Ebitda e a capacidade inovativa, possivelmente influenciada pela relação negativa com a inovação em marketing. Os resultados da análise individual das variáveis apontam relações positivas quando se inova no produto, especialmente quando o produto é novo para o mercado nacional e o principal produto é completamente novo para a empresa. Há, no entanto, uma relação negativa quando a empresa inova em processo já existente no país e conhecido por seus concorrentes nacionais.

REAd | Porto Alegre - Edição 81 - N 2 - maio/agosto 2014 - p. 269-299 
A CAPACIDADE INOVATIVA E O DESEMPENHO ECONÔMICO-FINANCEIRO DE

\section{EMPRESAS INOVADORAS BRASILEIRAS}

Assim, não se confirma a $\mathrm{H}_{2}$ da pesquisa, por indicar relação negativa entre a capacidade inovativa e o Ebitda. Destaque-se, no entanto, a utilização ótima da inovação de produto, não sendo identificada nos demais tipos de inovação.

\subsection{Relação entre a capacidade inovativa e o MVA $^{\circledR}$}

Analisa-se, neste tópico, se a capacidade inovativa reflete positivamente a geração de valor para as empresas, agregando valor para o acionista. Acredita-se que as políticas de inovação das empresas favoreçam a relação positiva entre essas variáveis, conforme estabelecido em $\mathrm{H}_{3}$. A Tabela 6 mostra os graus de correlação entre o MVA ${ }^{\circledR}$ e a capacidade inovativa, servindo de base para confrontações, a posteriori, com a regressão linear.

Tabela 6 - Graus de correlação entre a capacidade inovativa e o MVA ${ }^{\circledR}$

\begin{tabular}{l|c|c|c|c|c|c|c|c|c|c|c|c|c|c|c}
\hline Variável & \multicolumn{10}{c}{ Variável Independente } \\
Dependente & $(1)$ & $(2)$ & $(3)$ & $(4)$ & $(5)$ & $(6)$ & $(7)$ & $(8)$ & $(9)$ & $(10)$ & $(11)$ & $(12)$ & $(13)$ & $(14)$ & $(15)$ \\
\hline MVA & 0,24 & 0,12 & 0,15 & 0,07 & 0,17 & 0,14 & 0,21 & 0,09 & 0,22 & 0,13 & 0,13 & 0,15 & 0,11 & 0,18 & 0,16 \\
\hline Nota: (1) CAPINOV, (2) PROD_NOVO_EMP, (3) PROD_NOVO_BR, (4) PRINC_PROD, (5) INPROD, (6) \\
PROC_NOVO_EMP, (7) PROC_NOVO_BR, (8) PRINC_PROC, (9) INPROC, (10) NOVA_TEC_GEST, (11) \\
DIST_RESP_DEC, (12) INORG, (13) CONCEITO_MKT, (14) NOVO_DESIGN e (15) INMKT.
\end{tabular}

Fonte: Elaborado pelos autores.

Os dados da Tabela 6 indicam uma relação positiva entre o $\mathrm{MVA}^{\circledR}$ e todas as variáveis de capacidade inovativa, sugerindo o alinhamento com o que foi estabelecido em $\mathrm{H}_{3}$. Destaque-se que em todos os grupos de variáveis há graus relevantes, considerando-se os valores obtidos, em especial a variável inovação em marketing, impulsionada pelas mudanças no design do produto, até então influenciando negativamente os indicadores ROA e Ebtida.

Embora os graus de correlação positivos indiquem uma relação causal entre as variáveis, não se observou essa afirmativa na aplicação das regressões lineares (Tabela 7). Importa ressaltar que o teste de Hausman indicou o modelo de efeitos fixos para o MVA ${ }^{\circledR}$, muito embora, como os resultados não se apresentaram significativos nessa indicação, a regressão tenha sido analisada utilizando-se o modelo de efeitos aleatórios. 
Kléber Formiga Miranda, Alessandra Carvalho de Vasconcelos, Márcia Martins Mendes de Luca \& José Ednilson de Oliveira Cabral

Tabela 7 - Regressões para $\mathrm{H}_{3}-\mathrm{MVA}^{\circledR}$

\begin{tabular}{|c|c|c|c|c|}
\hline \multicolumn{5}{|c|}{ Regressão da Hipótese 3} \\
\hline \multicolumn{5}{|l|}{0,1186} \\
\hline MVA & Coef. & Std. Err. & $\mathrm{z}$ & $\mathrm{P}>|\mathrm{z}|$ \\
\hline CAPINOV & $0,0339361^{*}$ & 0,0182782 & 1,86 & 0,063 \\
\hline cons & 0,2838942 & 0,1053560 & 2,69 & 0,007 \\
\hline \multicolumn{5}{|c|}{ Regressão Complementar (variáveis da capacidade inovativa) } \\
\hline \multicolumn{5}{|l|}{0,0942} \\
\hline MVA & Coef. & Std. Err. & $\mathrm{z}$ & $\mathrm{P}>|\mathrm{z}|$ \\
\hline INPROD & $-0,0253990$ & 0,0583577 & $-0,44$ & 0,663 \\
\hline INPROC & 0,0856474 & 0,0546104 & 1,57 & 0,117 \\
\hline INORG & 0,0340312 & 0,0639982 & 0,53 & 0,595 \\
\hline INMKT & 0,0415028 & 0,059127 & 0,70 & 0,483 \\
\hline cons & 0,2875512 & 0,1068359 & 2,69 & 0,007 \\
\hline \multicolumn{5}{|c|}{ Regressão Complementar (variáveis individuais da capacidade inovativa) } \\
\hline \multicolumn{5}{|l|}{0,0516} \\
\hline MVA & Coef. & Std. Err. & $\mathrm{Z}$ & $\mathrm{P}>|\mathrm{z}|$ \\
\hline PROD_NOVO_EMP & $-0,0752926$ & 0,1402336 & $-0,54$ & 0,591 \\
\hline PROD_NOVO_BR & $-0,0249466$ & 0,1120724 & $-0,22$ & 0,824 \\
\hline PRINC_PROD & $-0,0926058$ & 0,1436322 & $-0,64$ & 0,519 \\
\hline PROC_NOVO_EMP & 0,1297355 & 0,1228715 & 1,06 & 0,291 \\
\hline PROC_NOVO_BR & $0,3011876^{* *}$ & 0,1386615 & 2,17 & 0,030 \\
\hline PRINC_PROC & $-0,1086955$ & 0,1381289 & $-0,79$ & 0,431 \\
\hline NOVA_TEC_GEST & 0,1966397 & 0,1370662 & 1,43 & 0,151 \\
\hline DIST_RESP_DEC & $-0,0638195$ & 0,1162467 & $-0,55$ & 0,583 \\
\hline CONCEITO_MKT & $-0,1361987$ & 0,1289827 & $-1,06$ & 0,291 \\
\hline NOVO_DESIGN & 0,1889406 & 0,1328032 & 1,42 & 0,155 \\
\hline _cons & 0,2254238 & 0,1073907 & 2,10 & 0,036 \\
\hline
\end{tabular}

Nota: Significante: $* 10 \%$ e $* * 5 \%$.

Fonte: Elaborado pelos autores.

Os resultados da Tabela 7 demonstram uma relação positiva entre o $\mathrm{MVA}^{\circledR}$ e a capacidade inovativa, levando à aceitação da $\mathrm{H}_{3}$. Dentre as demais variáveis, apenas inovações em processo novo para o Brasil (PROC_NOVO_BR) mostraram-se positivamente significantes. O panorama exposto sugere a geração de valor para o acionista através da capacidade inovativa das empresas, diferentemente das demais variáveis de desempenho.

Nessa perspectiva, infere-se que o mercado percebe quando a empresa adota políticas inovadoras, ao inovar no produto, no processo, na organização e em marketing, devido à REAd | Porto Alegre - Edição 81 - N 2 - maio/agosto 2014 - p. 269-299 
A CAPACIDADE INOVATIVA E O DESEMPENHO ECONÔMICO-FINANCEIRO DE

\section{EMPRESAS INOVADORAS BRASILEIRAS}

relação com a capacidade inovativa. Embora não se estabeleça um critério estatístico válido, julga-se importante destacar a relação positiva entre o $\mathrm{MVA}^{\circledR}$ e a mudança no design dos produtos e em novas técnicas de gestão. Essas variáveis apareciam nas demais análises como redutoras do desempenho empresarial, e se configuram nessa relação como positivas. Nota-se, assim, um contexto diferente quando se analisa uma variável inerente ao mercado.

Esperava-se constatar a relação positiva entre a capacidade inovativa e o desempenho econômico-financeiro, embora essa expectativa não tenha se confirmado na relação com o ROA, em que não houve significância, nem com o Ebitda, em que a relação significante foi negativa. Os achados de Ferreira, Marques e Barbosa (2007) sugerem haver um melhor desempenho por meio de uma maior capacidade inovadora, o que foi verificado apenas na relação do MVA ${ }^{\circledR}$, em consonância com Miranda, Gallon e Silva-Filho (2011), que acharam uma relação entre o valor de mercado e a inovação, utilizando os valores dos intangíveis como proxy. Outro contraponto com os resultados de Ferreira, Marques e Barbosa (2007) diz respeito à inovação de processo. Para esses autores, corroborados pelos achados de Silva (2008), a inovação de processo é a maior geradora de desempenho, embora, na presente pesquisa, observe-se essa afirmativa apenas quando relacionada com o MVA ${ }^{\circledR}$.

Dentre as variáveis derivadas da capacidade inovativa, a inovação de produto é a única que desponta como determinante para um melhor desempenho empresarial, com resultados positivos e significativos para o ROA e para o Ebitda. Gomes e Kruglianskas (2009b) analisaram a relação de algumas práticas de gestão de fontes externas de informação tecnológica com o desempenho inovador da empresa, e identificaram a carência de uma perspectiva estratégica para a gestão dessas fontes.

Os resultados aqui apresentados são consistentes, considerando-se a afirmativa de Ribeiro, Rosseto e Verdinelli (2010), indicando que qualquer recurso possuído pela empresa não significa, objetivamente, uma fonte de vantagem competitiva, tal como a capacidade de gerar valor econômico superior aos de seus concorrentes. Para os autores, as empresas devem ter evidência do comportamento estratégico para usufruir os benefícios advindos dos recursos, e não apenas focar em tê-los. Assim, converge-se para os preceitos de diferenciação propostos pela VBR, com reconhecimento dessas iniciativas nos desempenhos econômico, operacional e de valor de empresas de capital aberto listadas na BM\&FBovespa, enquadradas nas atividades econômicas consideradas pelo IBI como intensivas em pesquisa e desenvolvimento, de onde se pressupõe haver estratégias robustas de inovação.

REAd | Porto Alegre - Edição 81 - N 2 - maio/agosto 2014 - p. 269-299 
Kléber Formiga Miranda, Alessandra Carvalho de Vasconcelos, Márcia Martins Mendes de Luca \& José Ednilson de Oliveira Cabral

A Figura 2 mostra um resumo dos resultados, apresentando para cada variável da capacidade inovativa os indicadores de desempenho econômico-financeiro com relação significante e o seu respectivo indicativo de relação, positiva ou negativa.

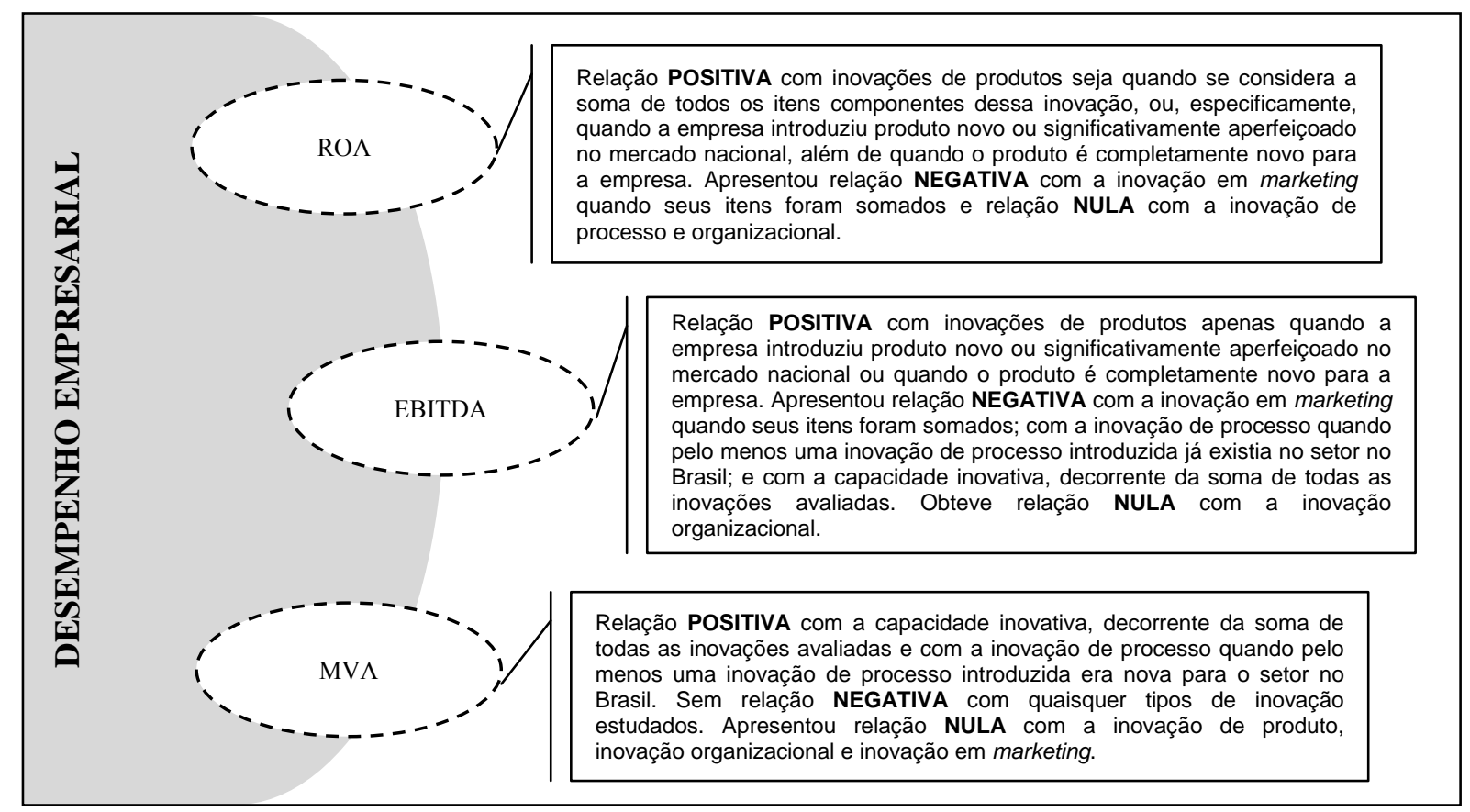

Figura 2 - Resumo dos principais resultados Fonte: Elaborado pelos autores

Considerando as informações da Figura 2, observa-se que as empresas brasileiras de capital aberto estudadas nesta pesquisa tem uma propensão para a melhoria do resultado contábil quando se inova no produto, dada as relações positivas verificadas com o ROA e o EBITDA, em especial quando as empresas introduzem produto novo ou significativamente aperfeiçoado no mercado nacional, ou ainda, quando seu principal produto é completamente novo para a empresa. Em contrapartida, inovar em marketing gera resultado oposto.

As outras formas de inovação não apresentaram significância. Assim, não se pode inferir sobre seu relacionamento com o desempenho econômico-financeiro das empresas pesquisadas.

Porém, como se trata de uma pesquisa voltada à verificação de diferenciais competitivos não se pode afirmar, também, a ausência de competitividade ao se inovar no processo, na inovação organizacional ou em marketing. A ausência de significância demonstra que esses tipos de inovação produzem efeito mais disperso por se tratar de estratégias ocorridas no âmbito interno da empresa. A inovação no produto produz impacto direto na receita e, por conseguinte nos indicadores contábeis de desempenho analisados. 
A CAPACIDADE INOVATIVA E O DESEMPENHO ECONÔMICO-FINANCEIRO DE

\section{EMPRESAS INOVADORAS BRASILEIRAS}

Dessa forma, apesar dos resultados apontados, as empresas podem adquirir diferenciais competitivos quando são eficazes na inovação em processo, organizacional e/ou marketing.

Foi possível constatar, ainda, impactos negativos significantes na variável EBITDA quando se inova no processo e em marketing; possivelmente explicados pelo reconhecimento contábil de despesas com essas inovações diretamente no resultado da empresa no período de sua ocorrência, já que esse indicador demonstra a potencialidade de geração de fluxo de caixa.

A relação positiva entre a capacidade inovativa total da empresa e o MVA demonstra a percepção do mercado nas empresas com maior propensão em inovar. Assim, quanto maior o leque de inovação das empresas maior valor será atribuído, reforçando a ideia de constituir um portfólio ótimo de inovação voltado a manter-se competitivo no mercado.

\section{CONSIDERAÇÕES FINAIS}

O presente estudo objetivou analisar a relação entre a capacidade inovativa e o desempenho econômico-financeiro de empresas brasileiras, considerando nesse componente da inovação o meio de diferenciação entre as empresas, tornando-as competitivas em relação às demais. Buscou-se, portanto, respaldo teórico na VBR por considerar a geração de vantagem competitiva nas empresas advindas do processo inovativo endógeno. Para atingir o objetivo pretendido, inicialmente, foi examinada a capacidade inovativa de empresas brasileiras e avaliado o seu desempenho nas perspectivas econômica, operacional e de valor. A amostra utilizada reúne 73 empresas listadas na BM\&FBovespa, que possuem atividades relacionadas pelo IBI como inovadoras e com informações divulgadas na Pintec.

A análise descritiva dos dados revelou um valor médio da capacidade inovativa das empresas abaixo da metade do total possível, significando a alternância na política das empresas voltada para inovar em produto, processo, organização e marketing. Após avaliar o desempenho das empresas brasileiras, constataram-se valores abaixo de 1, por se tratar de índices, embora os valores médios do ROA, do Ebitda e do MVA ${ }^{\circledR}$ hajam se mostrado diferentes, reforçando a heterogeneidade das estratégias empresariais quanto aos indicadores de desempenho estudados, o que justifica a análise individual dos indicadores.

Da relação entre a capacidade inovativa e o desempenho econômico-financeiro, surgiram resultados divergentes, contudo importantes para a discussão. Os resultados das hipóteses da pesquisa sugerem que os desempenhos econômico $\left(\mathrm{H}_{1}\right)$ e operacional $\left(\mathrm{H}_{2}\right)$ não são impactados positivamente pela capacidade inovativa, inferindo-se que tais variáveis apenas absorvem informações dos investimentos realizados para geração de capacidade 
Kléber Formiga Miranda, Alessandra Carvalho de Vasconcelos, Márcia Martins Mendes de Luca \& José Ednilson de Oliveira Cabral

inovativa, por serem compostas de informações contábeis, sendo, portanto, baseadas no passado (custo). Por outro lado, o desempenho de valor $\left(\mathrm{H}_{3}\right)$, representado pelo $\mathrm{MVA}^{\circledR}$, composto por valor de mercado, apresenta relação positiva com a capacidade inovativa, indicando a geração de vantagem competitiva, retratada no aumento de valor das empresas.

Ainda assim, analisando-se as variáveis componentes da capacidade inovativa, foi possível constatar a relação positiva entre a inovação de produto e o ROA, impulsionada pela inovação de produtos novos para o mercado nacional, quando realizados pela própria empresa, devendo-se ponderar sobre sua estratégia de inovação em marketing, por apresentar relação negativa com o indicador. A análise do Ebitda indicou uma relação negativa com a capacidade inovativa, ocasionada, principalmente, pela inovação em marketing, embora se tenha observado uma relação positiva quando a empresa, individualmente, inova em produtos novos no mercado nacional e nos seus processos, independentemente de já existirem. $\mathrm{O}$ MVA $^{\circledR}$ apresentou-se como o único indicador com relação positiva com a capacidade inovativa direcionado pela inovação de processo quando esse é novo para o Brasil, indicando a percepção do mercado sob esse aspecto.

Dessa forma, conclui-se que a capacidade inovativa das empresas brasileiras é capaz de compor um recurso alinhado aos pressupostos da VBR quanto à vantagem competitiva. Há, contudo, uma indicação de que, dentre os tipos de inovação estudados, os mais próximos dos atributos indicados pela VBR (BARNEY, 1991) se referem à inovação em produtos completamente novos para a empresa e para o mercado nacional por serem os geradores de aumento dos desempenhos operacional e econômico. Tratando-se de interesse na geração de valor para o acionista, o atributo gerador de vantagem competitiva, conforme a VBR, está relacionado a existência de melhor portfólio inovativo, pois apenas a soma do conjunto de inovações causou impacto positivo no $\mathrm{MVA}^{\circledR}$, impulsionado pela inovação no processo e em marketing.

$\mathrm{Na}$ prática, identificar recursos diferenciadores capazes de gerar vantagem competitiva, como propõe a VBR, não é tarefa simples. As estratégias de inovação das empresas brasileiras de capital aberto, conforme os resultados da pesquisa, podem ser direcionadas para inovação de produto e processo. As inovações em marketing e na organização não proporcionaram resultados perceptíveis nos indicadores de desempenho analisados nessa pesquisa, fazendo parte, porém, do conjunto de inovações importantes para melhor percepção do mercado. Destarte, sendo essa a realidade para as empresas de capital 
A CAPACIDADE INOVATIVA E O DESEMPENHO ECONÔMICO-FINANCEIRO DE

\section{EMPRESAS INOVADORAS BRASILEIRAS}

aberto, consideradas inovadoras pela atividade que desenvolvem, pode-se inferir que é importante a observância dessas estratégias também por empresas de pequeno e médio porte.

Algumas limitações, como a escolha restrita de indicadores de desempenho, a forma de acesso e disponibilização da base de dados, bem assim a quantidade de empresas da amostra e a não segmentação das empresas estudadas, podem ter interferido nos resultados do estudo. O tempo da coleta dos dados também constitui uma limitação, sendo difícil a sua atualização dado o trâmite burocrático junto ao IBGE. Sugere-se, portanto, que futuras pesquisas concentrem-se na atualização dos dados com as bases das PINTECs posteriores a 2008, na ampliação da amostra (possível por meio da concatenação da base PINTEC com os dados da Pesquisa Industrial Anual - PIA, também do IBGE), na quantidade de períodos analisados e na escolha de novos indicadores e técnicas estatísticas.

\section{REFERÊNCIAS}

ASSAF NETO, A. Finanças corporativas e valor. São Paulo: Atlas, 2008.

ARAÚJO, A. M. P; ASSAF NETO, A. A contabilidade tradicional e a contabilidade baseada em valor. Revista Contabilidade \& Finanças, n. 33, p. 16-32, set./dez. 2003.

BARNEY, J. B. Firm resources and sustained competitive advantage. Journal of Management, v. 17, n. 1, p. 99-120, 1991.

BOEHE, D. M. et al. Papel das relações interorganizacionais e da capacidade de inovação na propensão para exportar. Revista Eletrônica de Administração, Porto Alegre, ed. 68, v. 17, n. 1, p. 87-117, jan./abr. 2011.

BRITO, K. N.; CÂNDIDO, G. A. Difusão da inovação tecnológica como mecanismo de contribuição para formação de diferenciais competitivos em pequenas e médias empresas. Revista Eletrônica de Administração, Porto Alegre, ed. 32, v. 9, n. 2, p. 1-18, mar./abr. 2003.

BRITO, E. P. Z.; BRITO, L. A. L.; MORGANTI, F. Inovação e o desempenho empresarial: lucro ou crescimento? Revista de Administração de Empresas, São Paulo, v. 8, n. 1, art. 6, jan./jun. 2009.

BUCHANAN, D.; HUCZYNSKI, A. Organizational Behaviour: an introductory text. 5th. ed. Harlow: Prentice Hall, 2004. 
Kléber Formiga Miranda, Alessandra Carvalho de Vasconcelos, Márcia Martins Mendes de Luca \& José Ednilson de Oliveira Cabral

CAMERON, A. C.; TRIVEDI, P. K. Supplement to microeconometrics: methods and applications. New York: Cambridge University Press, 2005.

CAMPOS, B.; RUIZ, A. U. Padrões setoriais de inovação na indústria brasileira. Revista Brasileira de Inovação, v. 8, n. 1, p. 167-210, jan./jun. 2009.

CHAN, K. et al. Earnings Quality and Stock Returns. The Journal of Business. v. 79, n. 3, p. 1041-1082, mai. 2006.

COPELAND, T.; KOLLER, T.; MURRIN, J. Valuation: calculando e gerenciando o valor das empresas. 3. ed. São Paulo: Makron Books, 2002.

COZZARIN, B. P. Innovation quality and manufacturing firm's performance in Canada. Economics of Innovation and New Technology, v. 13, n. 3, p. 199-216, Apr. 2004.

CUNHA, N. C. V.; PALMA, M. A. M.; SANTOS, S. A. As práticas gerenciais promovendo a capacidade de inovação: estudo de múltiplos casos. Revista do Mestrado em Administração e Desenvolvimento. Empresarial da Universidade Estácio de Sá - Adm. MADE, Rio de Janeiro, ano 8, v. 12, n. 3, set./dez. 2008.

CUNHA, J. V. A.; COELHO, A. C. Regressão linear múltipla. In: CORRAR, L. J.; PAULO, E.; DIAS FILHO, J. M. (Org.). Análise multivariada: para os cursos de administração, ciências contábeis e economia. São Paulo: Atlas, 2009. p. 131-231.

FACÓ, J. F. B.; DUARTE, A. L. C. M.; CSILLAG, J. M. O efeito da TQM e da inovação no crescimento das empresas de manufatura do estado de São Paulo. Revista de Administração e Inovação, São Paulo, v. 6, n. 2, p. 44-57, 2009.

FERREIRA, J. J. M.; MARQUES, A. S. E.; BARBOSA, M. J. Relação entre inovação, capacidade inovadora e desempenho: o caso das empresas da região da beira interior. Revista de Administração e Inovação, São Paulo, v. 4, n. 3, p. 117-132, 2007.

FURMAN, J. L.; PORTER, M. E.; STERN, S. The determinants of national innovative capacity. Research Policy, v. 31, n. 6, p. 899-933, 2001.

FURTADO, A. et al. Índice Brasil de inovação: manual informativo sobre o procedimento de adesão das empresas. Campinas: UNICAMP/IG/DPCT e LABJOR, 2007. 28 f. 
A CAPACIDADE INOVATIVA E O DESEMPENHO ECONÔMICO-FINANCEIRO DE

\section{EMPRESAS INOVADORAS BRASILEIRAS}

GALLON, A. V.; REINA, D. R. M.; ENSSLIN, S. R. O impacto da inovação no desempenho econômico-financeiro das MPEIS catarinenses beneficiadas pelo programa juro zero (Finep). Revista de Contabilidade e Organizações, Ribeirão Preto, v. 4, n. 8, p. 112-138, jan./abr. 2010.

GARCIA, J. R. A importância dos instrumentos de apoio à inovação para micro e pequenas empresas para o desenvolvimento econômico. Revista FAE, Curitiba, v. 10, n. 2, p. 131-144, jul./dez. 2007.

GARCIA, R; CALANTONE, R. A critical look at technological innovation typology and innovativeness terminology: a literature review. The Journal of Product Innovation Management, n. 19, p. 110-132, 2002.

GOMES, C. M.; KRUGLIANSKAS, I. A influência do porte no comportamento inovador da empresa. Revista de Administração e Inovação, São Paulo, v. 6, n. 2, p. 5-27, 2009a.

. Indicadores e características da gestão de fontes externas de informação tecnológica e do desempenho inovador de empresas brasileiras. Revista de Administração Contemporânea, v. 13, n. 2, art. 1, p. 172-188, abr./jun. 2009 b.

GUJARATI, D. N. Econometria básica. Rio de Janeiro: Elsevier, 2006.

HURLEY, R. F.; HULT, G. T. M. Innovation, market orientation, and organizational learning: an integration and empirical examination. Journal of Marketing, v. 62, p. 42-54, July 1998.

IBGE - Instituto Brasileiro de Geografia e Estatística. Pesquisa de inovação tecnológica Pintec 2008: anexo 2 - questionário da pesquisa de inovação tecnológica 2008. Rio de Janeiro: IBGE, 2009. Disponível em: <http://migre.me/dcMO9>. Acesso em 11 fev. 2013.

KANNEBLEY JÚNIOR, S.; PORTO, G. S.; PAZELLO, E. T. Inovação na indústria brasileira: uma análise exploratória a partir da PINTEC. RBI - Revista Brasileira de Inovação, v. 3, n. 1, p. 87-128, jan./jun. 2004.

MALACHIAS, C. S.; MEIRELLES, D. S. Regime tecnológico, ambiente de inovação e desempenho empresarial no setor de serviços: um estudo exploratório das empresas de tecnologia da informação. Revista de Administração e Inovação, São Paulo, v. 6, n. 2, p. 5880, 2009. 
Kléber Formiga Miranda, Alessandra Carvalho de Vasconcelos, Márcia Martins Mendes de Luca \& José Ednilson de Oliveira Cabral

MATARAZZO, D. C. Análise financeira de balanços: abordagem gerencial. 7. ed. São Paulo: Atlas, 2010.

MELLO, A. M. et al. Innovative capacity and advantage: a case study of Brazilian firms. Revista de Administração e Inovação, São Paulo, v. 5, n. 2, p. 57-72, 2008.

MIRANDA, K. F.; GALLON, A. V.; SILVA-FILHO, J. C. L. Ativos intangíveis e grau de inovação como determinantes da maximização do valor das empresas brasileiras de grupos setoriais inovativos. In: CONGRESO LATINO-IBEROAMERICANO DE GESTIÓN TECNOLÓGICA - ALTEC, 14., 2011, Lima/Peru, Anais... Lima: PUCP, 2011.

; __ _ NOGUEIRA, L. C. B. Ativos intangíveis e grau de inovação: fatores influentes no desempenho econômico empresarial?. In: SIMPÓSIO DE ADMINISTRAÇÃO DA PRODUÇÃO - SIMPOI, 14., 2011, São Paulo. Anais... São Paulo: FGV-EASP, 2011.

OECD - Organisation for Economic Co-operation and Development. Oslo manual: proposed guidelines for collecting and interpreting technological innovation data. Paris: OECD, 2005.

PENROSE, E. T. The theory of the growth of the firm. Oxford: Basil Blackwell, 1959. 2006. . A teoria do crescimento da firma. Trad.: Tamás Szmrecsányi. Campinas: Unicamp,

PEREIRA, M. F. et al. Fatores de inovação para a sobrevivência das micro e pequenas empresas no Brasil. Revista de Administração e Inovação, São Paulo, v. 6, n. 1, p. 50-65, 2009.

PETERAF, M. A. The cornerstones of competitive advantage: a resource-based view.

Strategic Management Journal, n. 3, v. 14, p. 179-191, 1993.

RIBEIRO, R.; ROSSETTO, C.; VERDINELLI, M. A. Alinhamento dos recursos da empresa ao seu comportamento estratégico: uma agenda de pesquisa. Revista Desenvolvimento em Questão, Ijuí/RS, v. 8, n. 16, p. 103-130, jul./dez. 2010.

RICHARDSON, R. J. Pesquisa social: métodos e técnicas. 3. ed. São Paulo: Atlas, 2009.

ROESCH, S. A. Projetos de estágio e de pesquisa em administração: guia para estágios, trabalhos de conclusão, dissertações e estudos de caso. 3. ed. São Paulo: Atlas, 2006. 
ROUSE, M. J.; DAELLENBACH, U. S. Rethinking research methods for the resource-based perspective: isolating sources of sustainable competitive advantage. Strategic Management Journal, n. 20, p. 487-494, 1999.

SANTOS, D. F. L. A influência da inovação no desempenho das firmas no Brasil. 2009. 314 f. Tese (Doutorado em Administração de Empresas) - Centro de Ciências Sociais Aplicadas, Universidade Presbiteriana Mackenzie, São Paulo, 2009.

SANTOS, J. G. C.; VASCONCELOS, A. C.; DE LUCA, M. M. M. Perfil da inovação e da internacionalização de empresas transnacionais. In: SIMPÓSIO DE GESTÃO DA INOVAÇÃO TECNOLÓGICA, 27., 2012, Salvador, Anais... Rio de Janeiro: Anpad, 2012.

SCHREIBER, D.; BESSI, V. G.; PUFFAL, D. P.; TONDOLO, V. A. G. Posicionamento estratégico de MPE'S com base na inovação através do modelo hélice tríplice. Revista Eletrônica de Administração, Porto Alegre, ed. 76, n. 3, p. 767-795, set./dez. 2013.

SCHUMPETER, J. A. Teoria do desenvolvimento econômico: uma investigação sobre lucros, capital, crédito, juro e o ciclo econômico. 3. ed. São Paulo: Nova Cultural, 1988.

SILVA, M. J. A. M. Determinantes da capacidade inovadora empresarial ao nível da inovação no processo: modelo logit. In: INTERNATIONAL CONFERENCE AEDEM, 17., 2008, Salvador, Anais... Salvador: UFBA, 2008.

STAL, E. Internacionalização das empresas brasileiras e o papel da inovação na construção de vantagens competitivas. Revista de Administração e Inovação, São Paulo, v. 7, n. 3, p. 120 149, jul./set. 2010.

STOCK, J. H.; WATSON, M. K. Econometria. São Paulo: Addison Wesley, 2004.

TEECE, D. J.; PISANO, G.; SHUEN, A. Dynamic capabilities and strategic management. Strategic Management Journal, v. 18, n. 7, p. 509-533, 1997.

TEH, C. C.; KAYO, E. K.; KIMURA, H. Marcas, patentes e criação de valor. Revista de Administração Mackenzie, São Paulo, v. 9, n. 1, p. 86-106, 2008.

TIDD, J.; BESSANT, J.; PAVITT, K. Gestão da inovação. 3. ed. Porto Alegre: Bookman, 2008. 
Kléber Formiga Miranda, Alessandra Carvalho de Vasconcelos, Márcia Martins Mendes de Luca \& José Ednilson de Oliveira Cabral

VIOTTI, E. B. Brasil: de política de ciência e tecnologia para política de inovação? Evolução e desafios das políticas brasileiras de ciência, tecnologia e inovação. In: CGEE - CENTRO DE GESTÃO E ESTUDOS ESTRATÉGICO. Avaliação de políticas de ciência, tecnologia e inovação: diálogos entre experiências estrangeiras e brasileira. Brasília: CGEE, 2008.

WERNERFELT, B. A resource-based view of the firm. Strategic Management Journal, v. 5, n. 2, p. 171-180, 1984.

ZALTMAN, G.; DUNCAN, R.; HOLBEK, J. Innovations and organizations. New York: Wiley, 1973.

ZIMMERMANN, D. M.; CARIO, S. A.; RAUEN, A. Caracterização econômica e dinâmica inovativa das empresas de software em incubadora de base tecnológica em Santa Catarina. Revista Análise, Porto Alegre, v. 20, n. 1, p. 48-66, jan./jun. 2009. 